\title{
CHARACTERIZATION OF CARBON FIBROUS MATERIAL FROM PLATANUS ACHENES AS PLATINUM CATALYSTS SUPPORT
}

\author{
Branka V. Kaludjerovic ${ }^{1, *}$, Vladislava M. Jovanovic ${ }^{2}$, Sanja I. Stevanovic ${ }^{2}$, \\ Zarko D. Bogdanov ${ }^{l}$, Sanja S. Krstic ${ }^{l}$, Vladimir Dodevski ${ }^{l}$ \\ ${ }^{1}$ Vinča, Institute of Nuclear Sciences, University of Belgrade, \\ National Institute of the Republic of Serbia. \\ ${ }^{2}$ Institute of Chemistry, Technology and Metallurgy, National Institute \\ Department of Electrochemistry, University of Belgrade, Serbia.
}

Received 25.11.2020

Accepted 31.12.2020

\begin{abstract}
Carbon materials with developed porosity are usually used as supports for platinum catalysts. Physico-chemical characteristics of the support influence the properties of platinum deposited and its catalytic activity. In our studies, we deposited platinum on carbon fibrous like materials obtained from platanus seeds - achenes. The precursor was chemically activated with different reagents: $\mathrm{NaOH}$, pyrogallol, and $\mathrm{H}_{2} \mathrm{O}_{2}$, before the carbonization process. Platinum was deposited on all substrates to study the influence of the substrate properties on the activity of the catalyst. Carbon materials were characterized by nitrogen adsorption/desorption isotherms measurements, X-ray diffraction, and scanning electron microscopy. It was noticed that the adsorption characteristics of carbon support affected the structure of platinum deposits and thus their activity.
\end{abstract} oxidation

Keywords: active carbon material; achenes; platinum; catalyst; formic acid

\section{Introduction}

Great research efforts have been done in order to develop platinum catalysts with good activity, selectivity and stability for formic acid oxidation in acid solution due to the possible application in fuel cells $[1,2]$. Platinum (Pt) is a single-metal catalyst that shows significantly high catalytic activity for this reaction. However, pure $\mathrm{Pt}$ alone in a fuel cell system may be easily poisoned by the intermediate species. Also, the high cost of the Pt catalyst limits its commercial application as an electrocatalyst. To improve the utilization

${ }^{*}$ Corresponding author: Branka Kaludjerovic, branka@vin.bg.ac.rs 
of the Pt catalysts carbon materials are largely used as catalyst support. This is due to carbon material special properties such as relative stability in both acid and basic electrolyte, good conductivity, and high surface area for dispersion of metal catalyst, physico-chemical characteristics and surface chemistry of carbon that can influence properties of the support itself as well as of a catalyst [3-9].

According to Antolini [6], it is a great challenge to develop carbon supports with high specific surface area, suitable porosity, high electrical conductivity and high stability in a fuel cell environment. Carbon supports should possess a high proportion of mesoporous regions to provide a large surface area that is accessible to both the catalyst and the units of the Nafion ions to help excite the diffusion of the chemical species. That carbon materials can provide the high dispersion of Pt nanoparticles and at the same time enhance the electron transfer [6].

Active carbon materials can be made with a wide range of structures, compositions and properties, depending on the nature of the organic precursor, process and process parameters [3-14]. Amongst the precursors applied for the preparation of active carbon fibers are polyacrylonitrile (PAN) fiber, cellulosic fiber, phenol resin fiber or pitch fiber. To increase the durability of the catalyst the main requirement for catalyst support materials is a high specific surface area (should be greater than $100 \mathrm{~m}^{2} / \mathrm{g}$ ) [13]. To get a high surface area, physical or/and chemical activation processes of material have usually been employed. The activation of the material would provide a maximum substrate area for good dispersion of the Pt catalyst nanoparticle.

Some criteria of a potential support material that should be considered are: suitable porosity and porous structure, high stability in alkaline and acidic media, compatibility with the electrodes, and the additional water handling capability to prevent flooding in the catalyst layer [14]

A challenge in the field of carbon material supports is to produce very specific materials with a given pore size distribution from low-cost precursors. So, in this study, we examined a renewable type of a precursor for active carbon material-achenes from the Platanus orientalis seeds. Platanus fruit balls are about $2.5 \mathrm{~cm}$ in diameter and consist of several hundred seeds (achenes) densely packed together. The achene is about $1 \mathrm{~cm}$ long and $1 \mathrm{~mm}$ thick. A tuft of many thin stiff bristle fibers is attached to the base of each achene. The influence of different chemical activated agents on the porosity and electrochemical properties of carbon material support were examined.

\section{Experiment}

The Platanus seeds were peeled off and achenes soaked in the $10 \%$ aqueous solutions of $\mathrm{NaOH}$ (A1) Pyrogallol (A2) or $\mathrm{H}_{2} \mathrm{O}_{2}$ (A3), for one hour. The wet samples were dried at $100{ }^{\circ} \mathrm{C}$. These fibers were carbonized under Ar flow up to $900{ }^{\circ} \mathrm{C}$ and kept for $1 \mathrm{~h}$. After cooling under Ar flow the samples were washed with distilled water at 60 ${ }^{\circ} \mathrm{C}$. After that, the samples were grounded in a coffee mill. The final samples were denoted as AC1, AC2 and AC3 according to a number of soaked achenes.

The adsorption characteristics were determined from nitrogen adsorption/desorption isotherms at $77 \mathrm{~K}$ using the gravimetric McBain balance method. Specific surface area, $S_{B E T}$, and micropore volume, $V_{m i c}$, of the samples were calculated from the adsorption branch of the isotherm. The $S_{B E T}$ was calculated using BrunauerEmmet-Teller (BET) method. The values of $V_{\text {mic }}$ were calculated applying DubininRadushkevich equation. Total pore volume $V_{\text {tot }}$ is obtained under the assumption of the 
validity of the Gurvich rule which states that the amount adsorbed at the limiting plateau of an isotherm is a measure of the total adsorption capacity. Pore size distribution was estimated by applying the numerical method of Pierce modified by Orr and Dalla Valle on the desorption branch of the isotherm [15].

The crystalline structure was examined by X-ray diffraction analysis using $\mathrm{CuK} \alpha$ radiation (XRD, Siemens D500). The particle size of $\mathrm{Pt}$ was estimated from the broadening of the XRD reflections employing the Scherrer formula [16, 17].

The morphology was investigated by scanning electron microscopy (SEM, JEOL JSM-35 Model).

These carbonized seeds, as well as the Pt catalysts supported on these seeds, were characterized by the electrochemical method of cyclic voltammetry (CV). Pt catalysts were synthesized by the polyol method [18]. These samples were denoted as AC + Pt. The AC, as well as the catalysts $\mathrm{AC}+\mathrm{Pt}$, were applied in a form of a thin layer from the water-Nafion suspensions onto polished glassy carbon disk substrate. Both suspensions were prepared by ultrasonic homogenization during $1 \mathrm{~h}$. After each application, the electrode was dried in the air. CV measurements of samples were performed in $0.1 \mathrm{~mol}$ $\mathrm{dm}^{-3} \mathrm{HClO}_{4}$ with the sweep rates of 100, 50, 25 and $5 \mathrm{mV} / \mathrm{s}$. Carbonized seeds supported $\mathrm{Pt}$ catalysts were characterized by potential cycling between hydrogen and oxygen evolution regions at $50 \mathrm{mV} \cdot \mathrm{s}^{-1}$ in $0.1 \mathrm{~mol} \cdot \mathrm{dm}^{-3} \mathrm{HClO}_{4}$. The activities of the prepared $\mathrm{Pt}$ catalysts were studied in $0.1 \mathrm{M} \mathrm{HClO}_{4}+0.5 \mathrm{M} \mathrm{HCOOH}$ solutions upon their characterization by cyclic voltammetry. Formic acid was added while the potential was held at $-0.2 \mathrm{~V}$ and the positive-going scan was initiated with the rate of $50 \mathrm{mV} \cdot \mathrm{s}^{-1}$. All experiments were done at room temperature in a three-electrode-compartment electrochemical cell with Pt wire as a counter electrode and saturated calomel electrode (SCE) as the reference. The electrolytes were purged with purified nitrogen prior to each experiment. Electrochemical experiments were performed on AUTOLAB potentiostat/galvanostat PGStat 128N (MetrohmAutolab B.V., The Netherlands).

\section{Results and discussion}

The influence of activating agent on the adsorption characteristics of the carbonized achens obtained by $\mathrm{N}_{2}$ isotherms are presented in Fig. 1. and Tab. 1.

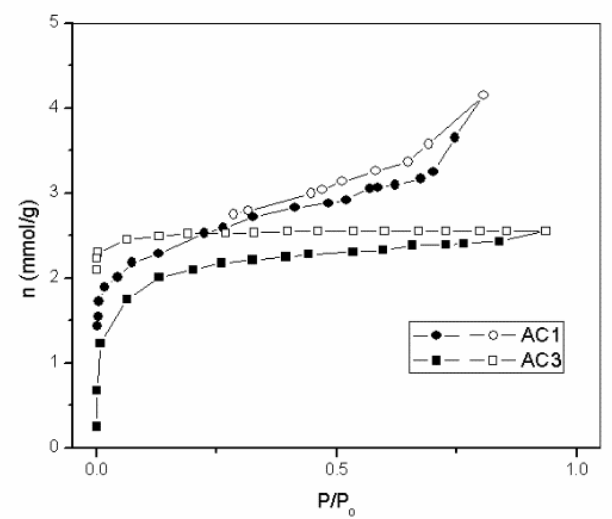

Fig. 1. Nitrogen isotherms for carbonized achens activated with $\mathrm{NaOH}(\mathrm{ACl})$ and $\mathrm{H}_{2} \mathrm{O}_{2}$ (AC3): -solid sign for adsorption and open sign for desorption. 
Figure 1 presents $\mathrm{N}_{2}$ isotherms of samples activated with $\mathrm{NaOH}(\mathrm{AC} 1)$ and $\mathrm{H}_{2} \mathrm{O}_{2}$ (AC3). These isotherms show that both activating agents induce specific surface area increases. Each isotherm exhibits a hysteresis loop, which is associated with filling and emptying of the mesopores by capillary condensation.

Impregnation with chemical agents increases the adsorption characteristics of the carbonized seeds, but the adsorption capacities strongly depend on the chemical agent used. Pyrogallol and $\mathrm{H}_{2} \mathrm{O}_{2}$ as chemical agents induced a slight increase of specific surface area $S_{B E T}$ after carbonization comparing with achens carbonized without impregnation (about $4 \mathrm{~m}^{2} / \mathrm{g}$ ). The specific surface area of carbonized achens and AC2 were calculated from results obtained in one point measurement due to poor adsorption characteristics, while the $S_{\mathrm{BET}}$ of carbonized AC1 and AC3 were obtained by analysis of the multipoint adsorption. The obtained results are presented in Tab. 1.

Table 1. Adsorption characteristics of the carbonized achens.

\begin{tabular}{lccc}
\hline Sample & $S_{\text {BET }}\left(\mathrm{m}^{2} / \mathrm{g}\right)$ & $V_{\text {mic }}\left(\mathrm{cm}^{3} / \mathrm{g}\right)$ & $V_{\text {tot }}\left(\mathrm{cm}^{3} / \mathrm{g}\right)$ \\
\hline AC1 & 377 & 0.070 & 0.144 \\
AC2 & 17 & - & - \\
AC3 & 162 & 0.064 & 0.088 \\
\hline
\end{tabular}

Hydroxides are generally very effective for the preparation of active carbon material [10], which is confirmed in this case, too; see Fig. 1 and Tab. 1. The results obtained for $S_{\text {BET }}$ of achens AC1 activated by $\mathrm{NaOH}$ is triple larger than the surface area of achens AC3 activated by $\mathrm{H}_{2} \mathrm{O}_{2}$.

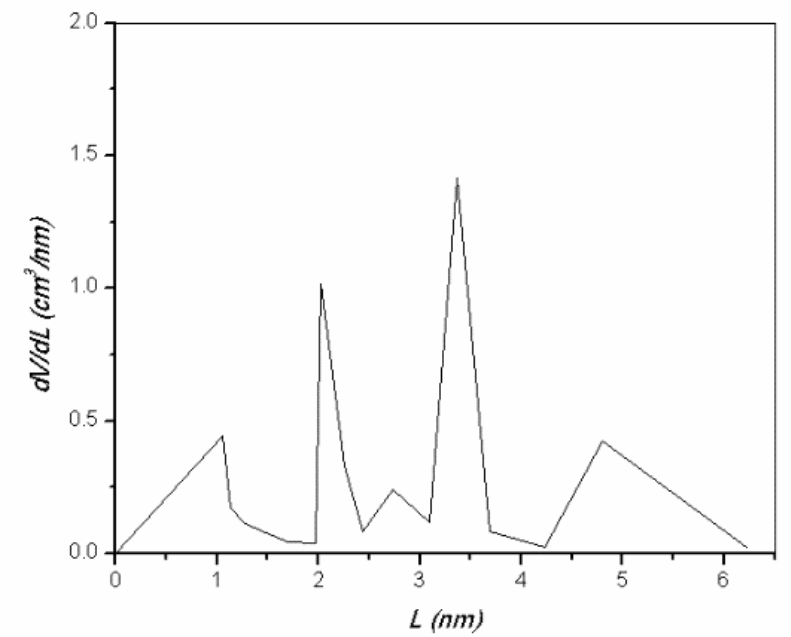

Fig. 2. Pore size distribution for ACl carbonized achens activated with $\mathrm{NaOH}$.

Micropores developed during the chemical activation of seeds by hydroxide were supermicropores $(>0.7 \mathrm{~nm})$, as shown in Figure 2. Sample AC1 mostly consists of the small mesopores (pore size $L$ is between 2 and $6 \mathrm{~nm}$ ). Sample AC3 only consists of the micropores with $L$ in the range from 0.5 to $1 \mathrm{~nm}$. These results agree with the results obtained for $V_{\text {mic }}$ and $V_{\text {tot }}$, for both samples, see Tab. 1 . 


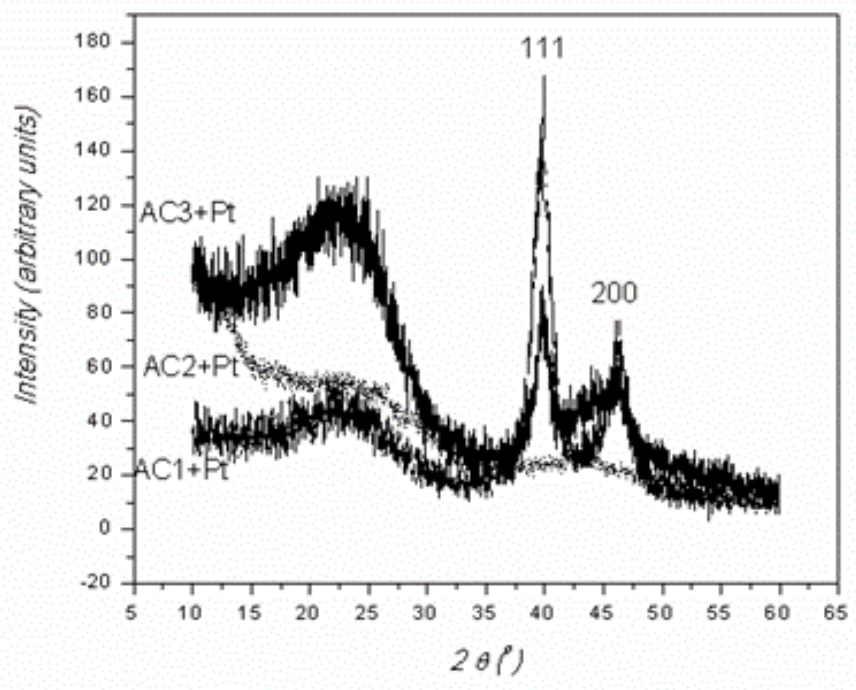

Fig. 3. XRD patterns of carbonized achenes ACl and AC3 loaded with Pt.

Results of XRD analysis are presented in Fig. 3. The XRD sample patterns are strongly influenced by activated carbon reflections, and the Pt reflections are not seen clearly, especially for sample AC2+Pt. The carbonized achens can contain some crystalline carbon structures indicated by the presence of a clear $(002)$ band in the $2 \theta$ region $22-25^{\circ}$ and (10) weak band at $\sim 43^{\circ}$. Further peaks placed at about $39.8^{\circ}, 46.2^{\circ}$ (see Fig. 3 and Tab. 2) are associated with the (111), (200) planes, respectively, of the face-centered cubic (fcc) crystalline Pt. There is no Pt reflection peak for sample AC2+Pt only the reflections for crystalline carbon.

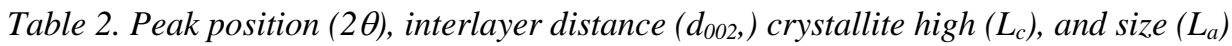
for different reflections of AC+Pt sample.

\begin{tabular}{lcccc}
\hline Sample & $\begin{array}{c}2 \theta \\
{\left[{ }^{\circ}\right]}\end{array}$ & $\begin{array}{c}d_{002} \\
{[\mathrm{~nm}]}\end{array}$ & $\begin{array}{c}L_{c} \\
{[\mathrm{~nm}]}\end{array}$ & $\begin{array}{c}L_{a} \\
{[\mathrm{~nm}]}\end{array}$ \\
\hline $\mathrm{AC} 1+\mathrm{Pt}$ & 22.60 & 0.393 & 2.75 & - \\
& 39.86 & & & 6.24 \\
$\mathrm{AC} 2+\mathrm{Pt}$ & $24.94 ; 43.20$ & 0.357 & 1.01 & 3.30 \\
$\mathrm{AC} 3+\mathrm{Pt}$ & $23.80 ; 43.46$ & 0.373 & 1.27 & 3.18 \\
& 39.84 & & & 7.49 \\
\hline
\end{tabular}

The (002) band indicates the spacing of the aromatic ring layer i.e., interlayer spacing $d_{002}$. These observations suggest that the carbonized achenes support crystallites have a random layer lattice structure so-called turbostratic structure. The position of this peak is found to shift to a higher $2 \theta$ value with an increase in elemental carbon content [19]. In this case, the sample AC2+Pt has the lowest $d_{002}$. which is to be expected, because it is made by the reduction process and has the lowest porosity. 
The Lateral size $(L a)$ and the stacking height $(L c)$ of the crystallite are determined using the Sherrer equation $[16,17]$. The results of XRD analysis are presented in Tab. 2.

Sample $\mathrm{AC} 1+\mathrm{Pt}$ crystallite high $L_{c}$ is larger than in the case of the other two samples AC2+Pt and AC3+Pt. But this sample has no $L_{a}$, or its reflection placed at about $43^{\circ}$ couldn't be seen clearly due to nearby (200) Pt position.

Platinum grain size, obtained from its [111] reflection peak for $\mathrm{AC} 1+\mathrm{Pt}$ and $\mathrm{AC} 3+\mathrm{Pt}$, is $6.24 \mathrm{~nm}$ and $7.49 \mathrm{~nm}$, respectively. The grain size of platinum corresponds to the pore size of sample AC1 (see Fig.2), which indicates that platinum may have been located in the mesopores of this sample. This is not the case for the AC3 sample, consisting mainly of micropores, so it is assumed that the platinum grains are distributed on the sample surface.

Morphology of activated nature fibers differs that could be seen at SEM micrographs (Fig. 4).

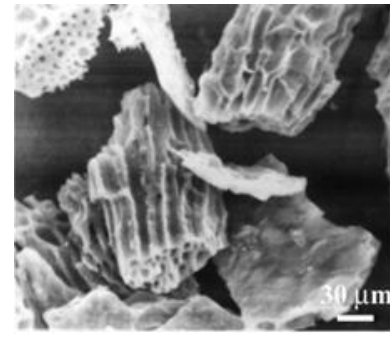

(a)

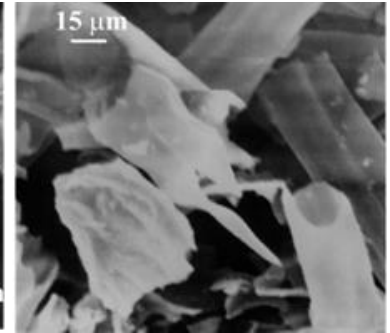

(b)

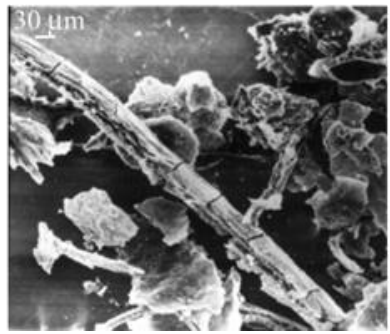

(c)

Fig. 4. SEM micrographs of carbonized achenes: (a) AC1, (b) AC2, and (c) AC3.

Sample AC2 has a smooth surface (Fig. 4 (b)), while activation of achenes by hydroxide (Fig. 4 (a)) or peroxide (Fig. 4 (c)) results in surface roughness of the material.

The influence of the chemical agent used for activation of carbonized achenes was also analyzed by cyclic voltammetry, see Fig. 5. The results obtained showed that none of the samples exhibited pure double layer properties. Also, each of them poses some quantity of functional groups raveled by more or less defined redox peaks, similar to most other carbon materials [20], as for example, Vulcan XC presented in Fig. 5.

The specific capacitance calculated from CVs for carbonized achenes AC1-3 are presented in Tab. 3. The increase in charge is related to an increase in porosity, i.e., specific surface area $S_{\mathrm{BET}}$. Based on data from the electrochemical measurements, the activity and porosity of the activated fibers is in order of AC1 > AC3>AC2.

Table 3. Total, the mesoporous and microporous capacitance of the carbonized achens AC calculated from cyclic voltammetry data

\begin{tabular}{llll}
\hline Sample & Ctot $(\mathrm{F} / \mathrm{g})$ & $C_{\text {mic }}(\mathrm{F} / \mathrm{g})$ & $C_{\text {meso }}(\mathrm{F} / \mathrm{g})$ \\
\hline AC1 & 222 & 203 & 19 \\
AC2 & 16 & 13 & 3 \\
AC3 & 18 & 16 & 2 \\
\hline
\end{tabular}




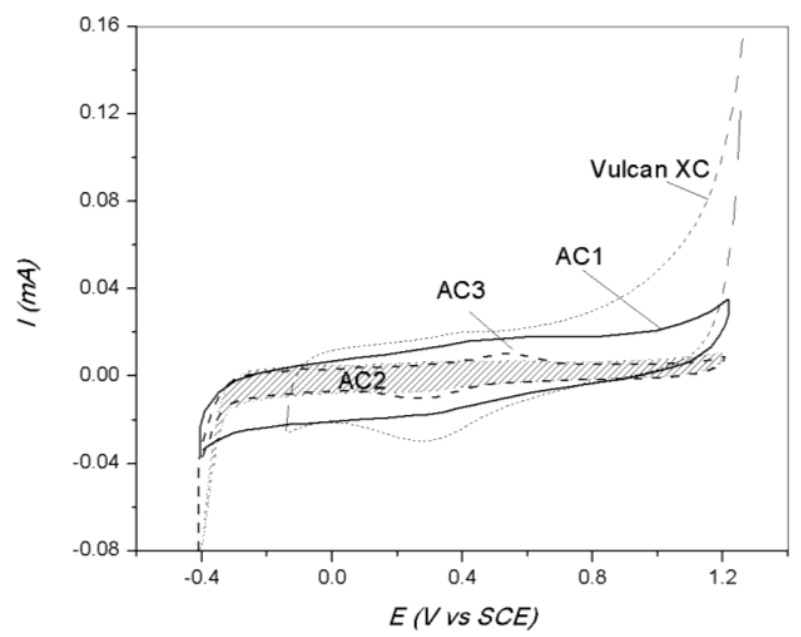

Fig. 5. Cyclic voltammograms of AC samples, and Vulcan XC applied on glassy carbon electrode in $0.1 \mathrm{M} \mathrm{HClO}_{4}$ solution; sweep rate $100 \mathrm{mV} / \mathrm{s}$.
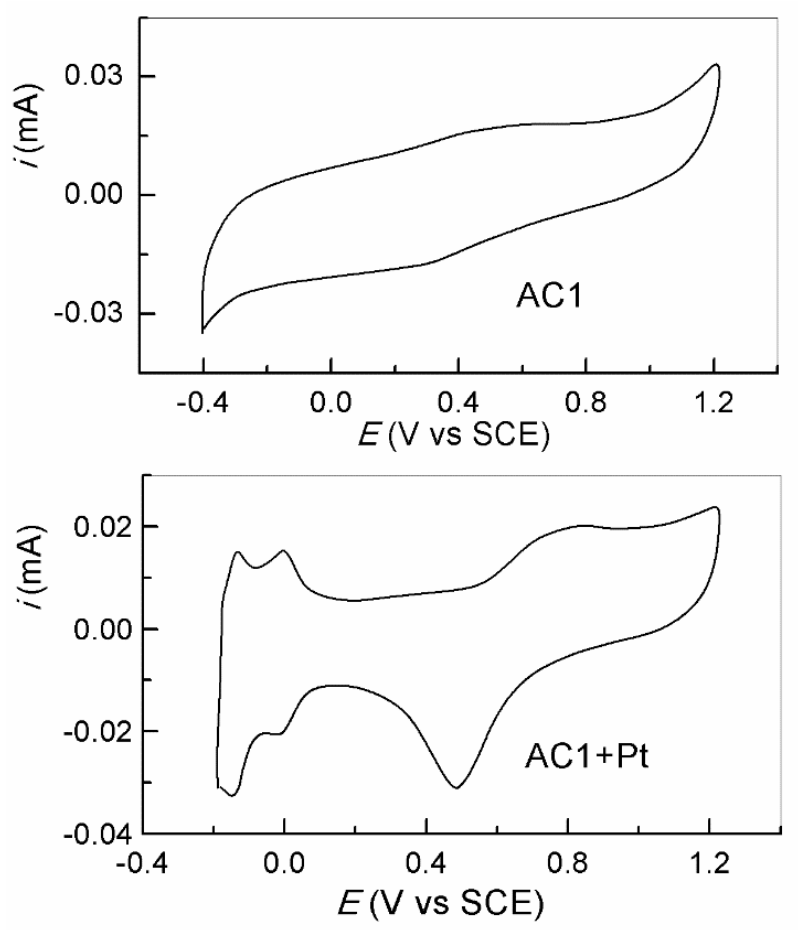

Fig. 6. Cyclic voltammograms of AC1 samples (upper) and AC1+Pt sample (lower) applied on glassy carbon electrode in $0.1 \mathrm{M} \mathrm{HClO4}$ solution; sweep rate $100 \mathrm{mV} / \mathrm{s}$. 
Cyclic voltammetry was also used for the characterization of Pt particles supported on different fibers. The cyclic voltammograms of Pt catalysts depending on the fiber support resemble the voltammogram for polycrystalline Pt electrode with more or less well defined hydrogen adsorption/desorption region $(-0.2 \mathrm{~V}<\mathrm{E}<0.15 \mathrm{~V})$ and region of surface oxidation at higher potentials (Fig. 6) for $\mathrm{AC} 1+\mathrm{Pt}$ and $\mathrm{AC} 3+\mathrm{Pt}$ electrodes. However, these regions are poorly outlined for $\mathrm{AC} 2+\mathrm{Pt}$ catalyst, and this electrode has not been examined further. Voltammograms of formic acid oxidation are characteristic for dual path reaction mechanism and similar in shape for $\mathrm{AC} 1+\mathrm{Pt}$ and $\mathrm{AC} 3+\mathrm{Pt}$ electrodes. The degree of the activity also differs regarding the oxidizing agent applied in the activation process, i.e. AC3+Pt electrode is about two times more active than $\mathrm{AC} 1+\mathrm{Pt}$ one. Formic acid oxidation on Pt electrodes follows the dual path mechanism [21]. Due to such mechanism oxidation of formic acid at Pt proceeds in the positive scan with a slowly increasing current which reaches a plateau at $\sim 0.25 \mathrm{~V} / \mathrm{SCE}$ and ascends again at $\sim 0.5 \mathrm{~V} / \mathrm{SCE}$ attaining a maximum at $\sim 0.62 \mathrm{VSCE}$. The slow increase of current at the low potential region is a result of the dehydrogenation i.e. the direct path, based on the oxidation of formate, as the active intermediate which does not need any oxygencontaining species [22] to be oxidized to $\mathrm{CO}_{2}$. Similarly, the parallel path proceeds to generate $\mathrm{CO}_{\mathrm{ad}}$ through dehydration which can be oxidized to $\mathrm{CO}_{2}$ only by oxygencontaining species formed at higher potentials. Increasing $\mathrm{CO}_{\mathrm{ad}}$ coverage reduces the $\mathrm{Pt}$ sites available for the direct path; the current slowly rises and reaches a plateau. Subsequent formation of oxygen-containing species on Pt enables the oxidative removal of $\mathrm{CO}_{\mathrm{ad}}$, more $\mathrm{Pt}$ sites become available for $\mathrm{HCOOH}$ oxidation and current increases until Pt oxide, inactive for $\mathrm{HCOOH}$ oxidation, is formed, which results in the current peak at $\sim 0.62 \mathrm{~V} / \mathrm{SCE}$. Bearing in mind the importance of oxygen-containing species for oxidative removal of $\mathrm{CO}_{\mathrm{ad}}$, in this reaction mechanism, the difference in the activity between $\mathrm{AC} 1+\mathrm{Pt}$ and $\mathrm{AC} 3+\mathrm{Pt}$ is probably due to surface morphology and content of functional groups. Thus, the results obtained show the impact of the support properties on the properties of the Pt catalyst.

\section{Conclusion}

These investigations show that waste such as platanus seeds - achenes is a very promising raw material for active carbon materials production. The obtained materials in fact are short fibers and can be used as a catalyst support or as an adsorbent. An activating agent has an influence on the adsorption characteristics as well as on the structure and texture of the obtained material. Activation of the platanus seed influences Pt dispersion, particle size, and activity.

\section{Acknowledgments}

This work was financially supported by the Ministry of Education, Science and Technological Development of the Republic of Serbia.

\section{References}

[1] S. Sharma, B.G. Pollet: J Power Sources, 208 (2012) 96-119.

[2] A.V. Tripković, K.Dj. Popović, J.D. Lović, V.M. Jovanović, A. Kowal: J Electroanal Chem, 572 (2004), 119-128. 
[3] L.R. Radovic: Carbon Materials for Electrochemical Energy Storage Systems: Advanced Materials and Technologies, F. Béguin and E. Frackowiak, Eds., CRC Press, Taylor\&Francis, Boca Raton, USA, 2010, 163-219.

[4] V.M. Jovanović, S. Terzić, A. V. Tripković, K. Dj. Popović, J. D. Lović: Electroceh Comm, 6 (2004) 1254-1258.

[5] C. A. Leon y Leon, L.R. Radovic: Chemistry and Physics of Carbon, V. 24, P.A. Thrower, Ed; Marcel Dekker, New York, 1994, 213-310.

[6] E. Antolini: Appl Catal B Environ, 88 (2009) 1-24.

[7] B. V. Kaludjerović, V. M. Jovanović, B. M. Babić, S. Terzić, Ž. Bogdanov: J Optoelectron Adv Mater, 10 (2008) 2708 - 2712.

[8] Y. Ichin, K. Mitamura, N. Saito, O.Takai: J Vac Sci Technol A, 27 (2009) 826830.

[9] B. V. Kaluđerović, DJ. Čokeša, V. Dodevski, S. Krstić, V.M. Jovanović: Zastita Materijala, 56 (2015) 409 - 412.

[10] K. Sattler, Carbon Nanomaterials Sourcebook, Vols I and II Taylor \& Francis, Boca Raton, USA, 2016.

[11] B.V. Kaludjerović, V.M. Jovanović, S.I. Stevanović, Ž.D. Bogdanov: Ultrason Sonochem, 21 (2014) 782-789.

[12] Z.A.C. Ramli, S. K. Kamarudin: Nanoscale Research Letters, 13 (2018) 410.

[13] S. Samad, K.S. Loh, W.Y. Wong, T.K. Lee, J. Sunarso, S.T. Chong, W.R.W. Daud: Intern J Hydrog En, 43 (2018) 7823-7854.

[14] Y.-J. Wang, B. Fang, H. Li, X. T.Bi, H. Wang: Progress in Materials Science, 82 (2016) 445-498.

[15] S.J. Gregg, K.S.W. Sing: Adsorption, Surface Area and Porosity, second ed., Academic Press, London, 1982.

[16] V. Radmilović, H.A. Gasteiger, P.N.J. Ross: J Catal, 154 (1995) 98-106.

[17] K.A. Carrado, G. Sandi, R. Kizilel, S. Seifert, N. Castagnola: Appl Clay Sci, 30 (2005) 94-102.

[18] Y. Wang, J. Zhang, X. Wang, J. Ren, B. Zuo, Y. Tang: Topics in Catalysis, 35 (2005) 35-41.

[19] B. Manoj, A.G. Kunjomana: Int J Electrochem Sci, 7 (2012) 3127 - 3134.

[20] K. Kinoshita, J.A.S. Bett: Carbon, 12 (1974) 525-533.

[21] A. Capon, R. Parsons: J Electroanal Chem, 45 (1973) 205.

[22] A. Cuesta, M. Escudero, B. Lanova, H. Baltruschat: Langmuir, 25 (2009) 6500.

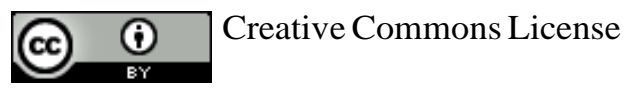

This work is licensed under a Creative Commons Attribution 4.0 International License. 